\title{
POSITION LIMIT FOR THE CSI 300 STOCK INDEX FUTURES MARKET
}

\author{
LIJIAN WEI ${ }^{1,4}$, WEI ZHANG ${ }^{2,3}$, XIONG XIONG $^{2,3, *}$ AND LEI SHI ${ }^{4}$ \\ ${ }^{1}$ Sun Yat-sen Business School, Sun Yat-sen University, Guangzhou 510275, PR China \\ ${ }^{2}$ College of Management and Economics, Tianjin University, Tianjin 300222, PR China \\ ${ }^{3}$ China Center for Social Computing and Analytics, Tianjin University, Tianjin 300072, PR China \\ ${ }^{4}$ UTS Business School, University of Technology, Sydney, PO Box 123, Broadway, NSW 2007, \\ Australia
}

\begin{abstract}
Acknowledgement: This research was supported by NSFC Grants (71131007, 71271145), the Program for Changjiang Scholars and Innovative Research Team (No. IRT1028), the Ph.D. Programs Foundation of the Ministry of Education of China (No. 20110032110031), Australian Research Council Grants (DP110104487, DP130103210), and a joint project of China Financial Futures Exchange (CFFEX), "Analysis of Stock Index Futures Trading Mechanism: From the Agent-based Modeling Perspective". We thank Carl Chiarella, Xuezhong He, Steven Li, Youwei Li, Xinbin Lin, Wencai Liu, Qi Nan Zhai, Yu Zhao, and the guest editor, Qiaoqiao Zhu, and two anonymous referees for their helpful comments and suggestions. We acknowledge Chao Xu, Haichuan $\mathrm{Xu}$, and Hongli Che for their assistance, and thank the CFFEX research center for data support. This paper is extracted from the final research report of the joint project submitted to CFFEX in February 2012; on May 31, 2012, CFFEX announced an increase in the position limit of the CSI 300 index futures to 300, in accordance with the policy suggestion in this paper. The views expressed here are those of the authors and do not necessarily reflect the view of CFFEX. The contents of this paper are the sole responsibility of the authors.
\end{abstract}

*Corresponding author; Tel. +86 22 27891308; Fax: +86 2227891308.

Emails: weilijian@gmail.com (Wei), weiz@tju.edu.cn (Zhang), xxpeter@tju.edu.cn (Xiong) and lei.shi@uts.edu.au (Shi). 


\section{Position Limit for the CSI 300 Stock Index Futures Market}

Abstract. The aim of this study was to find the optimal position limit for the Chinese Stock Index (CSI) 300 futures market. A low position limit helps to prevent price manipulations in the spot market, and thus keeps the magnitude of instantaneous price changes within the tolerance range of policy makers. However, setting a position limit that is too low may also have negative effects on market quality. We propose an artificial limit-order market with heterogeneous interacting agents to examine the impact of different levels of the position limit on market quality, measured as liquidity, return volatility, efficiency of information dissemination, and trading welfare. The simulation model is based on realistic trading mechanisms, investor structure, and order submission behavior observed in the CSI 300 futures market.

Our results show that on the basis of the liquidity status in September 2010, raising the position limit from 100 to 300 could significantly improve market quality and at the same time keep the maximum absolute price change per 5 seconds below the $2 \%$ tolerance level. However, the improvement becomes only marginal if the position limit is further increased beyond 300. Therefore, we believe that raising the position limit to a moderate level can enhance the functionality of the CSI 300 futures market, which should benefit the development of the Chinese financial system.

Keywords: Position limit, stock index futures, agent-based modeling, market quality.

JEL Classification: G14, C63, D44 


\section{INTRODUCTION}

The Chinese economy is growing rapidly and is now the second largest economy in the world. However, the Chinese financial market remains underdeveloped and requires further improvements in functionality for comparability with other international financial markets. The Chinese Stock Index (CSI) 300 futures market was introduced on April 16, 2010 in an effort to improve the country's financial system. The CSI 300 futures market allows investors to take short positions on futures to provide a hedge against risk arising from the Chinese stock market. Introduction of the futures market was considered a milestone that would bring the Chinese financial market into a new era.

However, during the first phase after its introduction, the CSI 300 futures market has not performed well because many of the market participants are individual investors who supplied little liquidity to the market. One possible reason is that the position limit of the CSI 300 futures market was too conservative. To ensure a safe launch and to prevent market manipulation, the initial position limit for the CSI 300 futures market was set to 100 contracts, which might have been insufficient for institutional investors 2 The low position limit of 100 could potentially inhibit institutional investors from taking optimal positions and providing sufficient liquidity to the market, which would lead to a low trading volume and order depth. Thus, investors suffer from the poor market quality. Therefore, policy makers face a trade-off between improving the market quality (by increasing the position limit) and preventing market manipulation (by keeping a low position limit). The question that arises is: What is the optimal level for the position limit?

Here we propose an agent-based model to simulate changes in market quality given different levels for the position limit. The market design and investor structure used in our model are chosen to best mimic the CSI 300 futures market. We first conduct an empirical study and find that a position limit of 371 should be sufficient if policy makers want to prevent manipulation and keep the instantaneous price change within a tolerance range of $2 \%$. Then simulation results for the agent-based model show that when the position limit is increased from 100 to 300, the market quality improves significantly. However, increasing the position limit beyond 300

\footnotetext{
${ }^{1}$ A position limit is the maximum unilateral position of a certain contract allowed to be held by members/customers. Security exchanges set position limits for two main reasons: (1) to prevent market manipulation by large institutions; and (2) to prevent the risk of a minority investor group holding a large unilateral position that might cause price fluctuations and defaults to spread into the entire market.

${ }^{2}$ Suppose the CSI 300 is at 2,000; as the value of one index point is $300 \mathrm{CNY}$, one speculative account can only conduct trades within the 60 million CNY limit, which is rather low compared to the CSI 300 market capitalization, which is greater than 13,000 billion CNY.
} 
leads to much less improvement in the market quality. Furthermore, our simulation results show that increasing the position limit to 300 does not lead to absolute price changes of more than $2 \%$. Therefore, we find that a position limit of 300 is close to being optimal for the CSI 300 futures market. The study also shows that agentbased modeling can be very useful for policy makers who need to make decisions in a complex environment (such as financial systems).

To provide some background information to understand why the position limit for the CSI 300 futures market was initially set to such a conservative level of 100, we first briefly review some of the important market events that occurred before the introduction of the CSI 300 futures market. The most serious incidence of market manipulation was the so-called " 3.27 " treasury futures incident, which occurred on March 27, 1995. Before this incident, Wanguo Security (WS), the largest security company in China at that time, held a long position of approximately 2 million contracts in treasury futures, and Zhongjingkai Security (ZS) held a short position of similar size. Both companies were highly leveraged, so a small price change could send either company to bankruptcy. In the afternoon of March 27, 1995, the Chinese Ministry of Finance decided to give a finance discount for treasuries, so the futures price rapidly increased and WS experienced losses of more than 6 billion CNY, which was five times the WS market value $3^{3}$ However, WS manipulated the market and sold huge orders to push the market price down; the last sell market order had a quantity of 7.3 million. $]^{4}$ This extreme trading behavior forced the Chinese treasuries futures market to close down and delayed the introduction of a stock index futures market for 15 years. Thus, when the CSI 300 futures market was introduced, regulators had serious concerns about market manipulation, which led to the low position limit of $1005^{5}$

Other international stock index futures markets also use position limits. For example, the position limit is 20,000 for the S\&P 500 and 10,000 for the Nikkei 225. However, some stock index future markets have no position limit, such as the Mini Dow stock index futures and the FTSE 100 stock index futures. Compared to these markets, the position limit for the CSI 300 futures market is very conservative. Intuitively, the optimal position limit should depend on market conditions. Some studies argue that position limits are not necessary. Gastineau (1991) and Telser (1993) argued that the position limits set by the SEC in the USA are not sufficient to prevent manipulation. Grossman (1993) suggested that position limits in the

\footnotetext{
${ }^{3} \mathrm{WS}$ did not go bankrupt because profits and losses were only realized when a position is closed.

${ }^{4}$ The value of this order was 146 billion CNY. There was no margin requirement to prevent WS from opening such a huge short position.

${ }^{5}$ In fact, in the preintroductory phase (simulation trading phase), the position limit was set to 600 , but it was then adjusted to 100 when the futures market was launched.
} 
futures markets simply move transactions from local to foreign markets, which does not help to prevent market manipulation. However, several studies support the idea that position limits place restrictions on market manipulation. Kyle (1984) developed a theoretical model of a commodity futures market and showed that position limits can reduce market manipulation. Kumar and Seppi (1992) conducted a sensitive analysis of market manipulation with two-stage asymmetric information in a cash-settled futures contract market. They found that market manipulation has a significant impact on liquidity. Thus, some studies support the idea that a position limit is helpful in preventing market manipulation; however, they do not provide ways to identify the optimal position limit given current market conditions.

Dutt and Harris (2005) proposed a theoretical model for setting an optimal position limit in a cash-settled futures market. They argued that surveillance and detection of market manipulation are difficult, and therefore regulators could set a position limit low enough to maintain instantaneous price changes within a tolerable range. The authors then examined prudent position limits among US financial derivative markets. However, they did not study the influence of position limits on market quality including liquidity, volatility, and pricing efficiency. To examine the impact of position limits on these indicators of market quality, we need to model the trading behavior of investors and examine the way in which a position limit affects the strategies used by traders. It is difficult to model trading behavior in a limit order market, which uses a continuous double auction trading mechanism and allows traders to make both market and limit orders.

Theoretical models are often not analytically tractable, as pointed out by Goettler, Parlour and Rajan (2009): "A model that incorporates the relevant frictions of limitorder markets (such as discrete prices, staggered trader arrivals, and asymmetric information) does not readily admit a closed-form solution." As a result, Goettler et al. (2009) used numerical methods to solve for equilibrium. Nevertheless, they needed to assume that order submission by uninformed traders is largely determined by an exogenously private value and that traders cannot learn from historical market data, which limits the applicability of their results to real markets.

An alternative approach is to use agent-based models. The advantages of agentbased models have been pointed out by Dawid and Fagiolo (2008): "The ability of ACE (agent-based computational economics) models to capture explicitly the relationship between structured interaction of heterogeneous individuals and the emerging patterns at the macroeconomic level, and to incorporate different types of boundedly rational individual behavior ". More importantly, in comparing agentbased models with neoclassical models, they further point out that "Political decision makers might be more willing to trust findings based on rather detailed simulation models where they see a lot of the economic structure they are familiar with than 
in general insights obtained in rather abstract mathematical models ". There has been progress in applying agent-based models for policy design. For example, Xiong, Wen, Zhang and Zhang (2011) analyzed the impact of different investor structures on market volatility in an artificial stock index futures market and illustrated a risk-diffusing mechanism in a cross-market structure. Moreover, Wei, Zhang, He and Zhang (2014) constructed an artificial limit-order market model with a continuous double-auction trading mechanism and study the efficiency of informationdissemination through the learning ability of the uninformed traders. Furthermore, Wei, Zhang, Xiong and Zhao (2014) set up an artificial stock index futures market based on the characteristics of the CSI 300 futures market and analyze how the minimum tick size affect market quality.

One of the drawbacks of agent-based models is the large number of parameters in the model and the lack of efficient methods for determining values for these parameters. To overcome this problem, we combine empirical analysis into our agent-based model in two steps. First, following Dutt and Harris (2005), we use empirical data from the CSI 300 futures market to find prudent position limits for different tolerance levels for instantaneous price changes. Then we use data on investor types and order submission to determine parameter values for the agentbased model and analyze the simulation results to examine whether increasing the position limit helps to improve market quality for the CSI 300 futures market.

The remainder of the paper is organized as follows. Section 2 uses empirical data from the CSI 300 futures market and follows Dutt and Harris (2005) to identify a prudent position limit to keep instantaneous price changes within a given tolerance range. Section 3 presents the agent-based computational model and describes the market set-up and the order submission rules. Section 4 examines the impact of increasing the position limits on the efficiency of information dissemination, price volatility, and liquidity. Section 5 concludes.

\section{Prudent position limits for the CSI 300 futures market}

In practice, it is very difficult to detect market manipulation and to distinguish manipulative from legitimate speculative activities. Dutt and Harris (2005) argued that surveillance and prosecution are inadequate for controlling market manipulation, and that setting a position limit is an alternative approach. They assumed that if instantaneous price changes are not greater than the tolerance level set by the regulator, then the regulator would not spend resources to distinguish manipulative from speculative trades. Therefore, manipulators may well be active in the market $6^{6}$ A prudent position limit can be generated from an analysis of the optimal behavior of a manipulator. For a given tolerance level for instantaneous price changes, the

\footnotetext{
${ }^{6}$ They may even act like speculators.
} 
objective of a manipulator is to maximize his profit from trades. It is assumed that price is a linear function of aggregate demand, and the prudent position limit is set such that it would not be optimal for the manipulator if price changes are greater than the tolerance level set by the regulator 7

Following Dutt and Harris (2005), we derive the prudent position limit $\theta^{*}$ according to

$$
\theta^{*}=\frac{D k}{500 m \varepsilon \sum_{i=1}^{300} \psi_{i} \omega_{i}},
$$

where $D$ is the sum of the value-weighted capitalization for constituent stocks in the initial period, $k$ is the tolerable price change, $m$ is the contract multiplier, $\varepsilon$ is an elasticity measuring market illiquidity, $\psi_{i}$ is the capitalization-value weight for the $i$ th component stock, and $\omega_{i}$ is the proportion of tradable shares of the $i$ th component stock. The derivation of the equation is described in Appendix A.

According to Equation 1, we calculate prudent position limits for the CSI 300 futures. Using data from the Guo Tai'an database $8^{8}$ we find $D=4,700,862,800$ CNY in the base period (December 31, 2004) and $\sum_{i=1}^{300} \psi_{i} \omega_{i}=0.009$. The contract multiplier is $m=300$. The tolerable price change $k$ is set to $1 \%$ for a low tolerance level and $2 \%$ for a high tolerance level ${ }^{9}$

Dutt and Harris (2005) evaluated $\varepsilon$ from the transaction cost prediction models of ITG and Goldman, which focus on US markets. Instead, we evaluate $\varepsilon$ as the market impact cost in the CSI 300 futures market according to the method of Almgren, Thum, Hauptmann and Li (2005). We choose 1-month high-frequency transaction data to estimate the market impact cost. The results are shown in Table 1. Data for the main contract $I F^{1009}$ are from August 23 to September 15, 2010 ${ }^{10}$ There are data for 18 trading days at 5-second time intervals, corresponding to 51,876 records in 18 days and 2,882 records per day ${ }^{11}$

\footnotetext{
${ }^{7}$ This method is useful for preventing the trade-based manipulation which generates strong price impact. Kong and Wang (2014) also reported the order-based manipulation which does not involve trade actions, but rather order actions in the Chinese financial markets. The order-based manipulation is hard to control by the position limit and beyond the scope of this paper.

${ }^{8}$ Guo Tai'an is the biggest data provider for Chinese financial markets.

${ }^{9}$ Dutt and Harris (2005) set $k$ to $3 \%$. However, owing the more serious concerns regarding manipulation in Chinese financial markets, we set the tolerable level for price changes to more conservative levels.

${ }^{10}$ We exclude three days for 1-month data: August 20, the first day that $I F^{1009}$ became the main contract and on which its volume changed a lot; September 17, the delivery day; and September 16, the day before delivery, because of a small trading volume.

${ }^{11}$ We also use the same period data including trading frequency, order profit, and order size to analyze investor behaviors. Statistical analysis of these indicators provides a basis for setting the parameters in our agent-based model, as described in the next section.
} 
Table 1 shows the value of $\varepsilon$ for different quantiles. Our results are similar to those of Dutt and Harris (2005). A larger $\varepsilon$ means that the market is more illiquid. We choose the $50 \%$ quantile as the normal state and the $90 \%$ quantile as the worst state for market liquidity.

\begin{tabular}{llllll}
\hline Quantile & $10 \%$ & $25 \%$ & $50 \%$ & $75 \%$ & $90 \%$ \\
\hline$\varepsilon$ & 144.6 & 162.3 & 187.8 & 230.1 & 312.6 \\
\hline
\end{tabular}

TABLE 1. Illiquidity elasticity estimates by market impact cost.

Now we can calculate the prudent position limits according to Equation 1. The results are reported in Table 2.

\begin{tabular}{lll}
\hline Illiquidity & $k \%=1 \%$ & $k \%=2 \%$ \\
\hline$\varepsilon=187.8$ & 185 & 371 \\
$\varepsilon=312.6$ & 111 & 223 \\
\hline
\end{tabular}

TABle 2. Prudent position limits for different tolerable price changes and illiquidity.

Table 2 shows that if the tolerable level is $1 \%$ and the market is very illiquid $(\varepsilon=312.6)$, the prudent position limit is 111 , which is close to the initial position limit of the CSI 300 futures market. However, if the Chinese regulators are willing to tolerate a $2 \%$ instantaneous price change, under the normal liquidity state, the prudent position limit can be as high as 371 . The question is whether increasing the position limit for the CSI futures market can significantly improve its market quality. To address this question, we conducted a simulation analysis using an agent-based model in a limit order market.

\section{Agent-Based computational model}

This section first describes the architecture of our agent-based computational model, including the tradable assets, market design, investor types, forecasting rules, order size, and order submission rules. Then we calibrate the parameters to create an artificial CSI 300 futures market (ACFM) and set different position limits suggested by the results obtained in Section 2 to examine the impact on market quality.

3.1. Fundamental value. Pricing theory for stock index futures implies a lead-lag relationship between futures and the underlying assets. Let $v_{t}$ be the fundamental value of a stock index futures with initial value $v_{0}$. In real markets, if the futures price deviates from its fundamental value, arbitragers will take short positions to 
push the futures price back to its fundamental. Owing to the no-short-selling in the Chinese underlying markets, investors can only do cash-and-carry arbitrage by shorting futures and taking a long position on the underlying stocks when the futures price is above its fundamental value. Therefore, we choose the cash-and-carry arbitrage ceiling for the CSI 300 futures market as the fundamental value. Cashand-carry requires the arbitrager to borrow at the market interest rate for a time horizon that matches the maturity of the futures contract to take long positions on the underlying stocks, and then take short positions on the futures. The cost of cash-and-carry provides a ceiling for the futures price, which we call the fundamental price. A detailed derivation of the fundamental price is provided in Appendix B, which incorporates the interest rate, transaction cost, market impact cost, dividend of underlying stocks, margin ratio, and time to maturity as key determining factors of the fundamental price. Owing to the transaction cost, the ceiling is always higher than the theoretical futures price, which is $e^{r T} S_{t}$. The difference between the ceiling and the theoretical price decreases as the maturity date approaches. As mentioned in Section 2, we use 5-second-interval data for the CSI 300 index from August 21 to September 15, 2010, to calculate the fundamental value. We generate a time series of fundamental values with 51,876 records, which we then use to run simulations in the ACFM.

3.2. Market design. To mimic trading in the CSI 300 futures market, we use a continuous double-auction trading mechanism that enables a trader to submit both limit and market orders, which are listed and matched in an electronic order book. The order book is emptied out at the end of every trading day (practice used in the CSI 300 futures market). During one trading period (5 seconds), there can be several or no transactions. The market price $p_{t}$ is the last transaction price at time $t$. If there are no transactions at time $t$, then we assume $p_{t}=p_{t-1}$. The initial market price is $p_{0}=v_{0}$. The transaction cost $\mu$ is set to $0.015 \%$ per transaction and the minimum tick size is set to $0.2 \mathrm{CNY}$. Furthermore, we initially set the position limit to 100, which is the same as the initial position limit in the CSI 300 futures market. Then we increase the position limit to higher levels to see whether the market quality significantly improves.

3.3. Investor types and structure. We consider an asymmetric-information framework for the agent-based model whereby a certain proportion of investors have private information about the future fundamental value. For example, large institutional investors might know more about the fundamental value because of better information-gathering abilities. The trading strategies of informed and uninformed traders have different characteristics. Menkhoff, Osler and Schmeling (2010) found that informed traders trade more actively than uninformed traders. Wei, Zhang, He 
and Zhang (2014) found that informed traders have a higher trading rate and make more profit than uninformed traders when information is short-lived.

Using high-frequency trading data for $I F^{1009}$ on September 6, 2011, we identify seven different ranges for the investor trading frequency. Table 3 classifies investors into four types according to their trading frequency, order profit, and transaction quantity. The data show that investors with a trading frequency greater than 135 gained the most profit on the day. These investors traded every 2 minutes on average. We call them informed traders and they accounted for $3.3 \%$ of the market traders. The second group is intelligent traders, who had an average trading frequency of 80 per day and an order return rate close to zero. They traded on average every 5 minutes and account for $6.4 \%$ of the market. Traders with lower trading frequencies had lower order profits. Simple traders make up $80.1 \%$ of the market, and their order return is on average between $-0.0389 \%$ and $-0.0331 \%$. The last group is liquidity traders, who traded once on the day and accounted for $10.1 \%$ of the market. Their orders made an average loss of $-0.1009 \%$. Therefore, it seems from the data that informed traders tend to trade more frequently and make profits from traders with lower trading frequencies, such as simple traders and liquidity traders. We recognize that this is only one trading day, but a similar pattern exists for other trading days in a similar time period.

\begin{tabular}{llllll}
\hline Type & Range of $f$ & Population & Proportion & Average of $f$ & Order return rate \\
\hline \multirow{3}{*}{ Informed traders } & $f \geq 270$ & 194 & & 417 & $0.0447 \%$ \\
& $135 \leq f<270$ & 279 & $3.3 \%$ & & 187 \\
\hline Intelligent traders & $54 \leq f<135$ & 915 & $6.4 \%$ & 80 & $0.0317 \%$ \\
\hline \multirow{3}{*}{ Simple traders } & $27 \leq f<54$ & 1580 & & 37 & $-0.0002 \%$ \\
& $9 \leq f<54$ & 4140 & $80.1 \%$ & 15 & $-0.0331 \%$ \\
& $2 \leq f<9$ & 5673 & & 4 & $-0.0351 \%$ \\
\hline Liquidity traders & $f=1$ & 1428 & $10.1 \%$ & 1 & $-0.1009 \%$ \\
\hline
\end{tabular}

TABLE 3. Statistics for high-frequency data for $I F^{1009}$ on September 6, 2011. $f$ is the trading frequency per day (270 minutes). The order return rate of trader $i$ is $r_{o}^{i}=\left(p_{o}^{i}-p_{c}\right) / p_{c}$ for a sell order and $r_{o}^{i}=$ $\left(p_{c}-p_{o}^{i}\right) / p_{c}$ for a buy order, where $p_{o}^{i}$ is the order transaction price and $p_{c}$ is the closing price on September 6, 2011. This is an approximation of investor profit since we cannot obtain data on actual investor profits because of privacy protection issues.

The information lag time $\tau$ is set according to the lead-lag relationship between stock index futures and the spot price. Sinolink Securities estimates that it is 
most likely that the CSI 300 futures price leads the spot price by approximately 2 minutes 12 which means that private information on the stock index futures market is released to the spot market after 2 minutes, so we assume that uninformed traders acquire the fundamental value with a lag of $\tau=2$ minutes.

The investor structure is based on statistical analysis of the CSI 300 futures market. The number of investors who enter the market is approximately 14,200 per day. However, because of limited computing power, we set the number of investors to 284 , which is approximately $1 / 50$ of the actual population. The number of informed, intelligent, simple, and liquidity traders were adjusted accordingly to 10, 18, 228, and 28, respectively.

We assume that investors arrive in the market according to a Poisson process with intensity $\phi_{i}$. The value of $\phi_{i}$ is set to $0.82,0.45,0.09$, and 0.008 for informed, intelligent, simple, and liquidity traders, respectively, according to statistics for the CSI 300 futures market. Several traders could enter the market in the same time period $t$, in which case we randomize their time priority according to a uniform distribution. Therefore, the precise time at which a particular investor enters the market is given by $t^{\prime}$ in period $t$. When an investor enters the market, he cancels any unexecuted limit order and submits a new buy/sell order of size $\left|q_{t}^{i}\right|$; a buy (sell) order would lead to a positive (negative) value for $q_{t}^{i}$. As explained later, we use the empirical probability distribution of the submitted order size to determine the distribution of $\left|q_{t}^{i}\right|$.

3.4. Investor forecasting rules for the fundamental value. We assume that all investors believe that the futures price will converge to its fundamental value. Therefore, investors make forecasts $p_{t^{\prime}}^{i}$ about the fundamental value. The forecasting rules of informed traders, intelligent traders, simple traders, and liquidity traders are given as follows.

(1) Informed traders almost know the fundamental value, but their forecast is contaminated by a random bias $\xi$ that follows a truncated standard normal distribution between -0.01 and 0.01 . We assume that each time an informed trader makes a forecast, there is a 10\% chance that a forecasting bias will occur. The forecasting rule is given by

$$
p_{t^{\prime}}^{i}=E_{t^{\prime}}^{i}\left(v_{t}\right)=v_{t}(1+\xi), \quad \xi \in[-0.01,0.01] .
$$

(2) An intelligent trader observes the $t-\tau$-period fundamental value $v_{t-\tau}$ when he enters the market. He also make use of the average trading price $\bar{p}_{t, \tau}$ of the past

\footnotetext{
${ }^{12}$ Sinolink Securities Special Reports for Stock Index Futures, 'Stock index futures lead stock index for 2 minutes and it contains multidimensional opportunities', 2010, China, in Chinese.
} 
$\tau$ periods and the bid-ask midpoint $p_{t^{\prime}}^{m}$, which are given by

$$
\bar{p}_{t, \tau}=\frac{1}{\tau}\left[p_{t-1}+p_{t-2}+\cdots+p_{t-\tau}\right], \quad p_{t^{\prime}}^{m}=\frac{1}{2}\left(a_{t^{\prime}}+b_{t^{\prime}}\right) .
$$

The forecasting rule of an intelligent trader $i$ is given by

$$
p_{t^{\prime}}^{i}=E_{t^{\prime}}^{i}\left(v_{t}\right)=\frac{1}{x_{t^{\prime}}^{i}+y_{t^{\prime}}^{i}+z_{t^{\prime}}^{i}}\left(x_{t^{\prime}}^{i} v_{t-\tau}+y_{t^{\prime}}^{i} \bar{p}_{t, \tau}+z_{t^{\prime}}^{i} p_{t^{\prime}}^{m}\right)
$$

where $x, y$, and $z$ are forecasting coefficients. Intelligent traders optimize the coefficients according to the genetic algorithm (GA). The values for $x, y$, and $z$ are bounded between 0.01 and 0.99. Appendix $\mathrm{C}$ provides details regarding the GA.

(3) The forecasting rule for simple traders is the same as that for intelligent traders except the values of $x, y$, and $z$ are selected randomly between 0.01 and 0.99 .

(4) Liquidity traders do not make any forecasts; they randomly select whether to submit either buy or sell market orders to meet their liquidity demand.

3.5. Order size under the position limit. The position limit has a significant impact on the order size. It is obvious that traders cannot submit an order of size greater than twice the position limit ${ }^{13}$

There are two ways to determine the order size. One way is to use a CARA risk preference utility to generate the demand of traders (2009), which has a theoretical foundation but is difficult to implement. Furthermore, it is unlikely that the order size in actual markets is close to the theoretically optimal demand because, for example, high-frequency traders usually break their trades into smaller sizes to minimize the market impact and have a zero net position at the end of each trading day. In addition, liquidity traders need to implement their liquidity demand in one transaction for special requirements ${ }^{14}$

We model order size using the second approach. To generate a realistic order flow, we estimate a probability density function (pdf) of order sizes based on empirical data for investor order submissions ${ }^{15}$. The pdf of $\left|q_{t}^{i}\right|$ is given by

$$
f^{i}(x)=\alpha^{i} e^{\beta^{i} x}+\gamma^{i} e^{\delta^{i} x},
$$

where $x \in(0, \infty)$ and $\alpha^{i}, \beta^{i}, \gamma^{i}$, and $\delta^{i}$ are the parameters for different trader types. We assume that the order size for type $i$ trader is i.i.d. for each period. The pdf specified in Equation (5) seems to best capture the empirical data. The fitted values for the parameters are presented in Table 4. According to the pdf $f^{i}(x)$, we generate

\footnotetext{
${ }^{13}$ We consider an extreme case, that is, when an investor has the maximum long position $\theta$ but wants to hold the maximum short position $\theta$, so the sell order size is $2 \theta$.

${ }^{14}$ For example, some index tracking funds need to adjust their position limit immediately.

${ }^{15}$ The data include 5-second high-frequency market data and the account data in the CSI 300 futures market from August 23 to September 15, 2010.
} 
an order size $\left|q_{t}^{i}\right|$ for trader type $i$. Fitting maps of the pdfs for the four investor types are presented in Appendix D.

\begin{tabular}{lllll}
\hline Investor type & $\alpha^{i}$ & $\beta^{i}$ & $\gamma^{i}$ & $\delta^{i}$ \\
\hline Informed traders & 0.2152 & -0.2130 & 0.0016 & -0.0081 \\
Intelligent traders & 0.8088 & -0.7682 & 0.0511 & -0.1107 \\
Simple traders & 5.1980 & -2.1570 & 0.1077 & -0.3107 \\
Liquidity traders & 9.1840 & -2.4590 & 0.0916 & -0.5296 \\
\hline
\end{tabular}

TABLE 4. Parameters for the probability density function for investor order size.

Note that the pdf $f^{i}(x)$ is not bounded above; therefore, without a position limit, traders (especially informed traders) can submit large orders (either buy or sell) that may lead to large price fluctuations. However, introduction of a position limit $\theta$ truncates the distribution in the following way. Suppose that a trader enters the market at time $t$ and $N$ of his previous submitted orders were executed, indexed by $n=1, \cdots, N$, with sizes $\left|q_{n}^{i *}\right|$. We define the current holding of futures contracts by trader $i$ as

$$
Q_{t}^{i}=\sum_{n=1}^{N} q_{n}^{i *} .
$$

Since the net holding of trader $i$ cannot exceed $\theta$, when trader $i$ submits an order of size $\left|q_{t}^{i}\right|$ at time $t,\left|Q_{t}^{i}+q_{t}^{i}\right| \leq \theta$ must hold, which is equivalent to

$$
-\theta-Q_{t}^{i} \leq q_{t}^{i} \leq \theta-Q_{t}^{i}
$$

Therefore, if trader $i$ submits a buy (sell) order, $f^{i}(x)$ must be truncated at $x \leq \theta-Q_{t}^{i}$ $\left(x \leq-\theta-Q_{t}^{i}\right)$.

3.6. Order submission rules. For order submission rules, we follow Gil-Bazo, Moreno and Tapia (2007) and Wei, Zhang, He and Zhang (2014). If an investor's forecast $p_{t^{\prime}}^{i}$ of the fundamental value significantly differs from the actual fundamental value $v_{t}$, and the expected order profit is more than the transaction cost $\mu$, then the investor submits a market order, otherwise he submits a limit order. The bid-ask spread is denoted by $s_{t^{\prime}}=a_{t^{\prime}}-b_{t^{\prime}}$, and the limit order price is denoted by $p_{l}$. The submission rules are presented in Table 5 .

3.7. Experiment design. The experiments are based on prior empirical analysis outlined in Section 2. We set the position limit to 111, 181, 223, and 371 corresponding to the four states based on market illiquidity and the tolerable price change of the regulator. We examine the impact of increasing the position limit on volatility, liquidity, and the efficiency of information dissemination. On the basis of the results, we provide some policy implications. Since it is conventional to round off the 


\begin{tabular}{ll}
\hline Scenario & Order \\
\hline Case 1: There is at least one ask price and one bid price in the limited order book \\
$p_{t^{\prime}}{ }^{i}>a_{t^{\prime}}+\mu$ & Market order to buy \\
$a_{t^{\prime}}+\mu \geq p_{t^{\prime}}{ }^{i} \geq b_{t^{\prime}}-\mu \&\left|a_{t^{\prime}}-p_{t^{\prime}}{ }^{i}\right| \leq\left|p_{t^{\prime}}{ }^{i}-b_{t^{\prime}}\right|$ & Limit order to buy with $p_{l}=p_{t^{\prime}}{ }^{i}-\mu$ \\
$a_{t^{\prime}}+\mu \geq p_{t^{\prime}}{ }^{i} \geq b_{t^{\prime}}-\mu \&\left|a_{t^{\prime}}-p_{t^{\prime}}{ }^{i}\right|>\left|p_{t^{\prime}}{ }^{i}-b_{t^{\prime}}\right|$ & Limit order to sell with $p_{l}=p_{t^{\prime}}{ }^{i}+\mu$ \\
$p_{t^{\prime}}{ }^{i}<b_{t^{\prime}}-\mu$ & Market order to sell \\
Case 2: There are no bid prices & \\
$p_{t^{\prime}}{ }^{i}>a_{t^{\prime}}+\mu$ & Market order to buy \\
$p_{t^{\prime}}{ }^{i} \leq a_{t^{\prime}}+\mu$ & Limit order to buy with $p_{l}=p_{t^{\prime}}{ }^{{ }^{\prime}}-\mu$ \\
Case 3: There are no ask prices & \\
$p_{t^{\prime}}{ }^{i}<b_{t^{\prime}}-\mu$ & Market order to sell \\
$p_{t^{\prime}}{ }^{i} \geq b_{t^{\prime}}-\mu$ & Limit order to sell with $p_{l}=p_{t^{\prime}}{ }^{i}+\mu$ \\
Case 4: There are no ask or bid prices & \\
With probability 50\% & \\
With probability 50\% & \\
\hline
\end{tabular}

TABle 5. Order submission rules.

position limits to the nearest hundred, we modify the position limits to 100, 200, 300, and 400, and denote the experiments as Exp. 1, Exp. 2, Exp. 3, and Exp. 4, respectively. The position limit for Exp. 1 is the same as for the actual market, so this is referred to as the benchmark case.

Each experimental group was run 30 times with different random seeds to meet the statistical significance requirement. Each simulation was run for 51,876 periods using the fundamental value of the CSI 300 futures market calculated from the given data. The first 37,446 periods (13 days) were used for intelligent traders to learn and optimize the forecasting rules. The results are for the remaining 14,430 periods (5 days).

\section{Market QUALity ANALYSiS}

Analysis of the market quality is based on three indicators: market liquidity represented by transaction volume, order book depth and the bid-ask spread; pricing efficiency represented by information dissemination and the forecasting accuracy of uninformed traders; and market volatility represented by the standard deviation of 
the market price return (per period) and the maximum instantaneous price change. The trading welfare for each trader type is measured by their average order profit. We also report the simulated market price, order book, and trading volume in Appendix E. The results show that the model generates some of the stylized facts for the CSI 300 futures market.

4.1. Liquidity. We first examine trading volume since a higher trading volume would result in a larger commission for the exchange.

We use analysis of variance (ANOVA) to analyze sample differences among the experiment groups. Figure 1 shows a sharp increase in trading volume of $15.23 \%$ when the position limit $\theta$ increases from 100 to 200. There is a further increase of $4.34 \%$ when $\theta$ increases from 200 to 300 , and then no significant change when $\theta$ increases from 300 to 400.

Next we examine the change in order depth at the best quotes. Figures 2(a) and 2(b) show that the order depth increases by more than $30 \%$ when the position limit $\theta$ increases from 100 to 200 , then by more than $10 \%$ when $\theta$ increases from 200 to 300 , and finally by less than $5 \%$ when $\theta$ increases from 300 to 400 .

Furthermore, Figure 3 indicates that the bid-ask spread becomes slightly wider (albeit not statistically significant) when the position limit increases from 100 to 200, with no significant changes when the position limit is further increased.

Table 6 shows that the change in liquidity is mainly due to orders submitted by informed traders. The results indicate that when the position limit increases, informed traders submit more limit orders and market orders, and a greater proportion of the limit orders are executed. In contrast, we do not see similar changes for the other trader types. Furthermore, according to Table 6, when the position limit increases, informed traders submit many more limit orders than market orders, so they provide rather than consume liquidity, which is consistent with the increase in order depth. In addition, a greater proportion of the limit orders submitted are executed, which explains the increase in trading volume.

4.2. Information efficiency. We use the mean absolute error ( $M A E$ ) between the market price and the fundamental value proposed by Theissen (2000) to measure the convergence of the market price to the fundamental value, which reflects the market information efficiency. The $M A E$ is defined as

$$
M A E=\frac{1}{T} \sum_{t=1}^{T}\left|p_{t}-v_{t}\right| .
$$




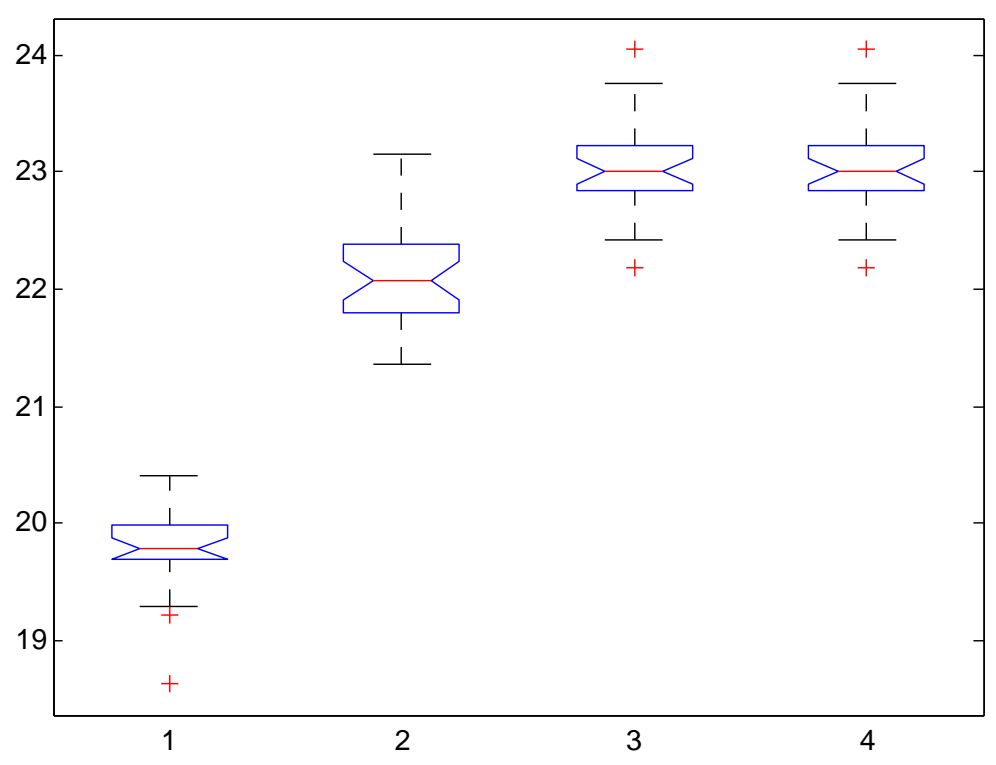

Figure 1. ANOVA for the trading volume. The $p$-value is less than $1 \%$.

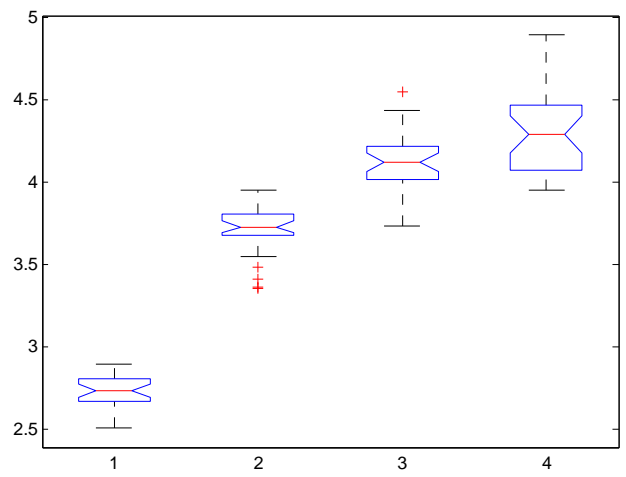

(a) Depth at bid.

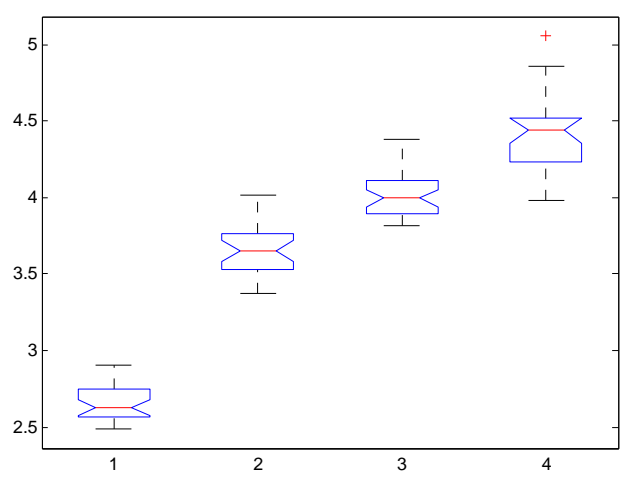

(b) Depth at ask.

Figure 2. ANOVA for the depth at bid and ask. The $p$-value for (a) and (b) is less than $1 \%$.

Similarly, we define the mean absolute deviation $(M A D)$ to measure the forecasting errors of intelligent traders (who use GA learning) and simple traders.

$$
M A D_{i}=\frac{1}{T} \sum_{t=1}^{T}\left|p_{t}^{i}-v_{t}\right| .
$$

Figure 4 shows that $M A E, M A D_{G A}$, and $M A D_{S}$ all decrease with the position limit, implying that there is an improvement in information efficiency. Moreover, the increase in information efficiency is statistically significant when the position limit increases from 100 to 200, and from 200 to 300. 


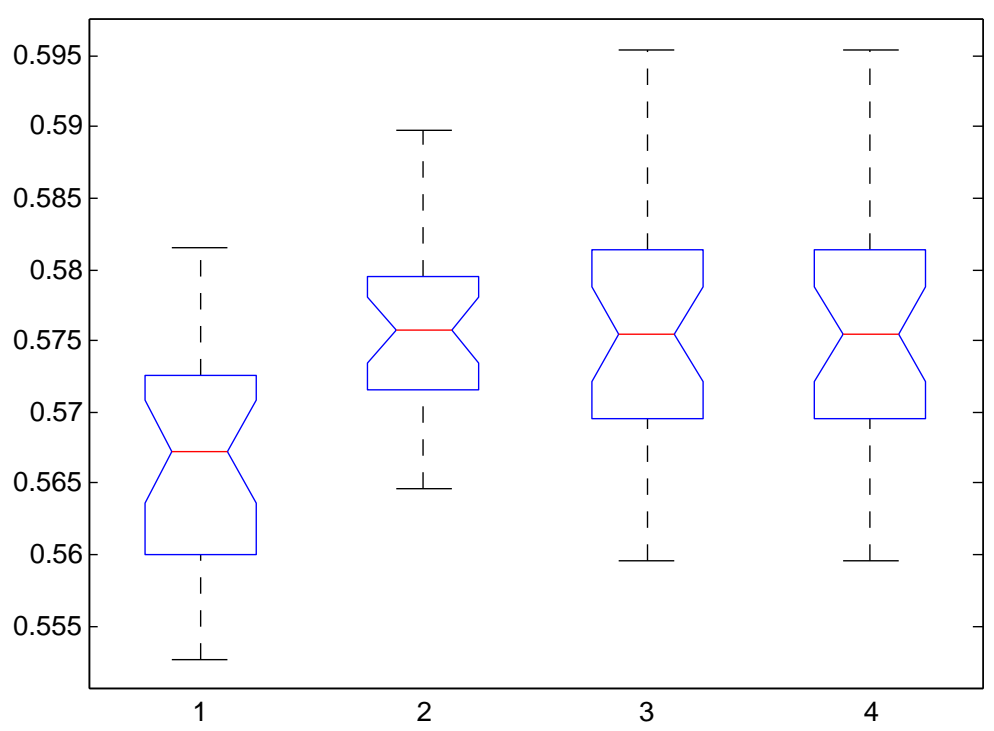

Figure 3. ANOVA for the bid-ask spread. The $p$-value is less than $1 \%$.

\begin{tabular}{ccccccccccc}
\hline Exp. & $I L O$ & $I M O$ & $I L E$ & $G A L O$ & GAMO & GALE & SLO & SMO & SLE & $L M O$ \\
\hline 1 & 435,173 & 160,838 & 63,764 & 305,335 & 12,384 & 23,208 & $2,345,139$ & 109,008 & 202,814 & 3,281 \\
2 & 706,961 & 202,329 & 96,711 & 323,998 & 12,480 & 25,029 & $2,361,872$ & 100,682 & 201,257 & 3,277 \\
3 & 827,075 & 219,762 & 111,447 & 333,148 & 12,257 & 25,777 & $2,358,265$ & 97,468 & 199,663 & 3,253 \\
4 & 899,885 & 233,725 & 122,185 & 336,724 & 12,390 & 26,253 & $2,362,954$ & 94,027 & 199,152 & 3,269 \\
\hline
\end{tabular}

TABLE 6. ILO, GALO, and $S L O$ denote the average number of limit orders submitted by informed, intelligent, and simple traders, respectively. Similarly, IMO, GAMO, SMO, and $L M O$ denote the average number of market orders submitted, and $I L E, G A L E$, and $S L E$ denote the average number of submitted limit orders that are executed for the three trader types.

This result is mainly driven by the fact that an increase in the position limit motivates informed traders to trade more aggressively, which helps to release information about the true fundamental value more quickly to intelligent traders.

4.3. Volatility. We use the standard deviation of the returns for transaction prices to measure volatility. As shown in Figure 5, volatility increases with the position limit $\theta$, which is most significant when $\theta$ increases from 100 to 200, from approximately 11.175 basis point (bp) to over $12.25 \mathrm{bp}$, which is a proportional increase of $6.4 \%$. There are no significant changes in volatility when $\theta$ is further increased to 300 or 400. Intuitively, volatility increases because informed traders trade more aggressively and submit a larger number of market orders, which actually improves the dissemination of information about the fundamental value. Therefore, the increase in volatility should not be interpreted as a deterioration in market quality; 


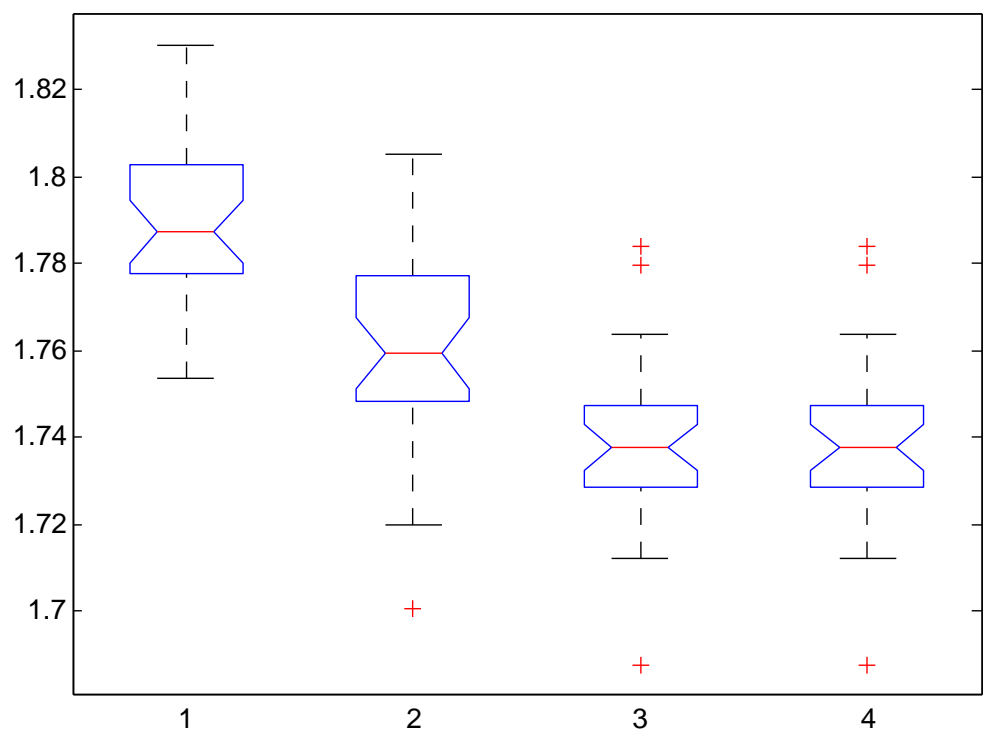

(a) $M A E$.

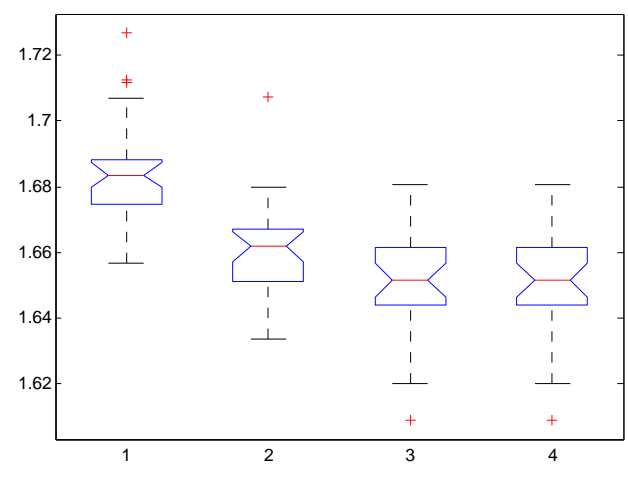

(b) $M A D_{G A}$.

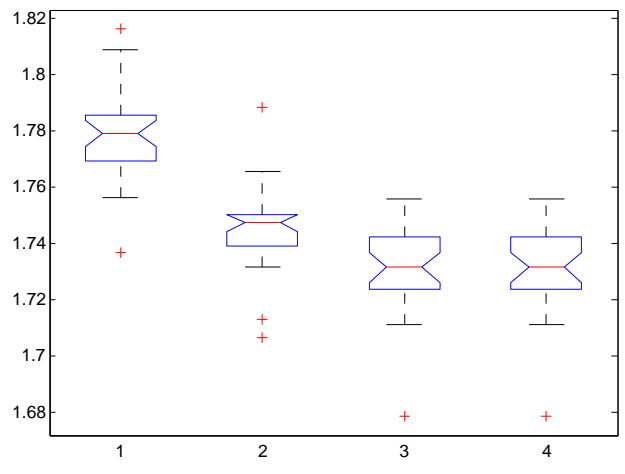

(c) $M A D_{S}$.

Figure 4. ANOVA for information dissemination indicators. $M A D_{G A}$ and $M A D_{S}$ are the $M A D$ for intelligent and simple traders, respectively. The $p$-value for (a), (b), and (c) is less than $1 \%$.

instead, it shows that an increase in the position limit helps the observed prices to better reflect information about the fundamental price, and thus improve market efficiency.

An important concern from the point of view of the market regulator is whether instantaneous price changes are below the tolerance level. According to the model of Dutt and Harris (2005), the instantaneous price change is an increasing function of the position limit set by the regulator, because it provides more incentives for manipulative trades in the spot market. However, our simulation results show that instantaneous price changes in the futures market never exceed $2 \%$, regardless of 


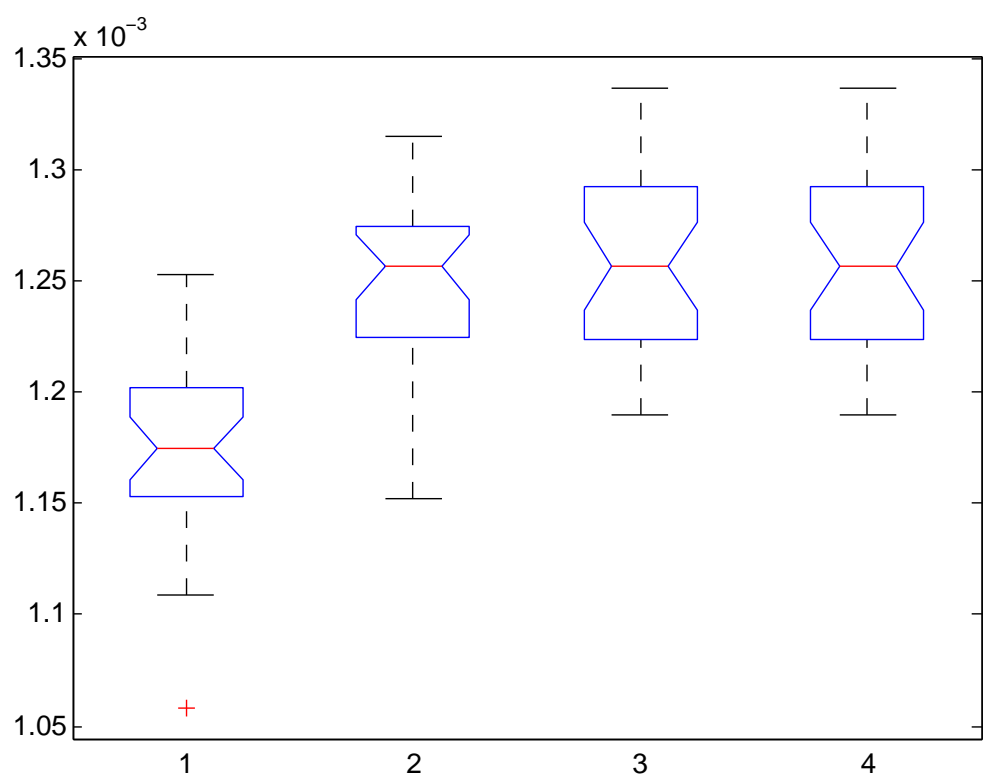

FigURE 5. ANOVA of the standard deviation of the market price return. The $p$-value is less than $1 \%$.

whether the position limit is set to $100,200,300$, or 400 . However, there are times when the instantaneous price change exceeds the $1 \%$ tolerance level.

We calculated the average number of times that price changes were greater than $1 \%$ over 30 simulations. Figure 6 shows that the average number of times the instantaneous price changes exceeds $1 \%$ does not change significantly as the position limit increases. Intuitively, although an increase in the position limit allows informed traders the possibility to submit large market orders, we see from Table 6 that informed traders actually submit a greater number of limit orders than market orders, which increases the order depth at the best bid and ask. Therefore, it seems likely that the larger market orders submitted by some informed traders are absorbed by larger limit orders submitted by the other informed traders.

4.4. Trading welfare. We finally consider order profits for the four trader types under different position limits. The order profit for an executed order is measured by $r_{t}=p_{t}-v_{t}$ for a sell order and $r_{t}=v_{t}-p_{t}$ for a buy order. We use $r_{I}$, $r_{G A}, r_{S}, r_{L}$ to denote the average profit per order (order size not considered) for informed, intelligent, simple, and liquidity traders, respectively. Similarly, $R_{I}, R_{G A}$, $R_{S}$, and $R_{L}$ denote the total profit for the four trader types taking order sizes into consideration.

Table 7 shows that the per order profit decreases for both informed and intelligent traders; however, the total profit increases for informed traders but decreases for intelligent traders. Intuitively, when the position limit is increased, informed traders 


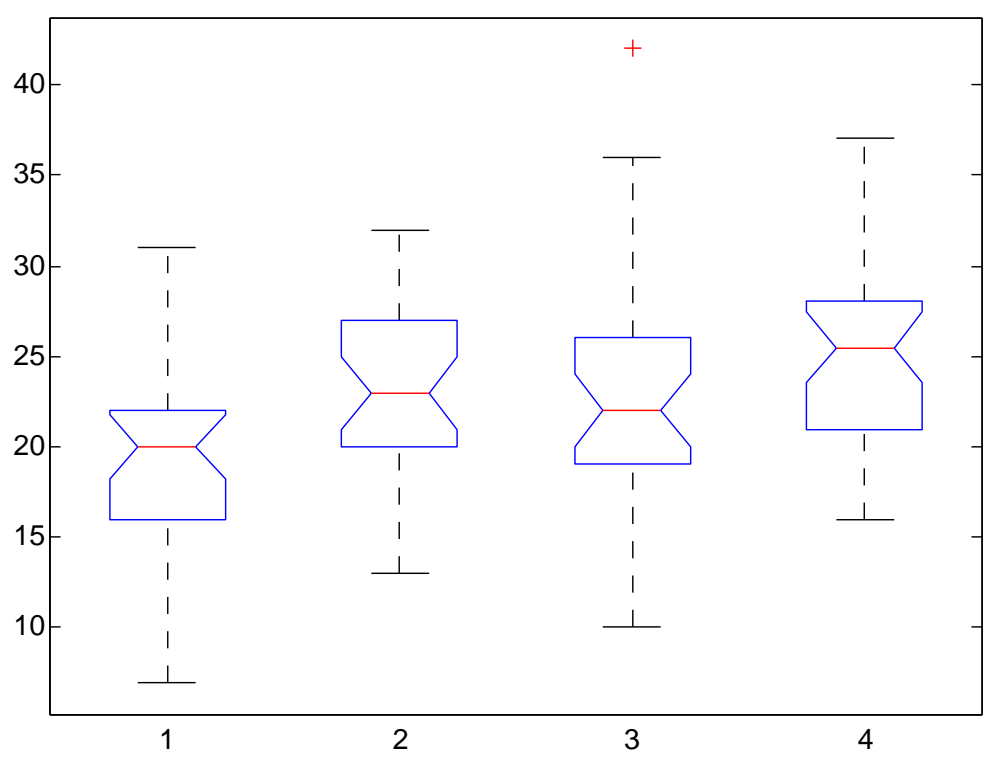

FiguRE 6 . ANOVA for the average number of times that the absolute price change for one period ( 5 seconds) exceeds $1 \%$. The $p$-value is less than $1 \%$.

submit larger orders, which leaks private information to intelligent traders, who use GA to try to extract the correct fundamental value from market information. However, the learning of intelligent traders is contaminated by the orders submitted by simple traders (liquidity traders are largely irrelevant because they only enter the market once a day). Therefore, although the orders submitted by informed traders becomes less profitable (per futures contract) as they submit larger orders, their total profit increases. The additional profit gained largely come from intelligent traders since the per order and total profits do not change significantly for simple and liquidity traders. Therefore, an increase in the position limit can potentially attract more informed traders (or institutional investors) to participate in the CSI 300 futures market to compete for additional profits.

\begin{tabular}{ccccccccc}
\hline Exp. & $r_{I}$ & $r_{G A}$ & $r_{S}$ & $r_{L}$ & $R_{I}$ & $R_{G A}$ & $R_{S}$ & $R_{L}$ \\
\hline 1 & 0.6572 & 0.5900 & -0.5383 & -0.2595 & 147,590 & 21,029 & $-167,766$ & -852 \\
2 & 0.5660 & 0.4112 & -0.6092 & -0.2546 & 169,218 & 15,447 & $-183,830$ & -835 \\
3 & 0.5352 & 0.3356 & -0.6371 & -0.2624 & 177,229 & 12,825 & $-189,200$ & -854 \\
4 & 0.5172 & 0.2532 & -0.6584 & -0.2798 & 184,025 & 9,782 & $-192,892$ & -915
\end{tabular}

TABLE 7. Order profit for the four trader types. $r$ is the order profit per unit and $R$ is the total order profit for each trader type. 


\section{Conclusion AND POLiCy implications}

We used an agent-based model with four investor types to examine the impact of an increase in the position limit on market quality for the CSI 300 futures market. Informed traders know the fundamental value, whereas intelligent traders attempt to learn about the fundamental value from market information according to the GA. Simple traders do not learn and simply try to guess the fundamental value from the lagged fundamental value and past prices. Finally, liquidity traders randomly supply and demand liquidity from the market. The four investor types are realistically identified using trading frequency and order return data for the CSI 300 futures market. Our model is designed to mimic all the important features of the actual market. Most importantly, we use the empirical distribution of the size of orders submitted to the CSI 300 futures market to determine the order size for each of the four investor types.

We find that an increase in the position limit helps to improve market quality. The simulation results show that when the position limit is increased from 100 to 300 , the trading volume increases by more than $20 \%$ and the order depth increases by $30 \%$ at the best quotes. Although the bid-ask spread increases slightly, the increase is not statistically significant. Information dissemination improves as market prices converge closer to the fundamental value. The standard deviation for market price returns increases by 8.2 bp per period when the position limit is increased from 100 to 300; however, we argue that this indicates that market prices better reflect information about the fundamental price rather than a deterioration in market quality. When the position limit is further increased from 300 to 400, there are no significant changes in market quality.

Of course, we recognize that investor characteristics such as trading frequency, trading strategy, and the distribution of order sizes are likely to evolve and adapt to increases in the position limit for the CSI 300 futures market. The assumption that these elements remain the same may not be innocuous if the position limit is increased by too much. Therefore, we recommend that regulators should first increase the position limit from 100 to 300 and monitor the market to see whether market quality indeed improves significantly as our model suggests. Then, after enough data have been gathered, the agent-based model can be resimulated with updated parameter values (estimated from newly observed market information) so that regulators can make better informed decisions on whether to further increase the position limit from 300 to a higher level. 


\section{APPENDIX}

\section{A. Derivation of prudent position limits for the CSI 300 futures market.} Following Dutt and Harris (2005), we derive prudent position limits for the CSI 300 futures market. Assuming that the underlying component price is a linear function ${ }^{16}$ with its true value and trading quantity as Equation A.1, where $P_{i}$ is the price associated with the $i$ th underlying index component, $V_{i}$ is its true value, and $Q_{i}$ is the aggregate trading quantity of manipulators in the underlying market. $\lambda_{i}$ is a measure of the illiquidity of the underlying market.

$$
P_{i}=V_{i}+\lambda_{i} Q_{i}
$$

CSI 300 index $I$ consisting of 300 underlying components is denoted by

$$
I=\frac{1000 \sum_{i=1}^{300} \omega_{i} g_{i} P_{i}}{D},
$$

where $\omega_{i}$ is the proportion of tradable shares ${ }^{17}$ of the $i$ th component stock, $g_{i}$ is the share factor, and $D$ is the sum of the value-weighted capitalization of the constituent stocks in the initial period. The value of a contract is $m I$, where $m$ is the contract multiplier ${ }^{18}$ for cash settlement. Let $\theta$ be the number of contracts that a trader holds. The notional value $Z$ of the traders contract position is

$$
Z=\theta m I=\frac{1000 \theta m}{D} \sum_{i=1}^{300} \omega_{i} g_{i} P_{i}=\frac{1000 \theta m}{D} \sum_{i=1}^{300} \omega_{i} g_{i}\left(V_{i}+\lambda_{i} Q_{i}\right) .
$$

The trading cost of manipulation per component $C_{i}$ is

$$
C_{i}=\left(V_{i}+\lambda_{i} Q_{i}\right) Q_{i}+c_{i} Q_{i}-V_{i} Q_{i}=\lambda_{i} Q_{i}^{2}+c_{i} Q_{i},
$$

where $c_{i}$ is the per-share commission rate. Thus, the total cost for manipulation of the underlying index is

$$
C=\sum_{i=1}^{300}\left(\lambda_{i} Q_{i}^{2}+c_{i} Q_{i}\right)
$$

The net profit from this manipulation is

\footnotetext{
${ }^{16}$ Dutt and Harris (2005) pointed out that the linear price function is widely accepted in market microstructure theory, as Kyle (1985) have provided a seminal analysis.

${ }^{17}$ In the Chinese stock markets, shares are divided into two categories. One category is nontradable shares, for which most of the owners are government entities, so-called "state shares"; the other category is tradable shares, which are held by normal shareholders. Most of the CSI 300 components comprise approximately two-thirds non-tradable shares.

${ }^{18}$ The value of a contract calling for cash settlement of $m$ times the value of the index; $m=300$ for CSI 300 futures index.
} 


$$
\Pi=Z-C=\frac{1000 \theta m}{D} \sum_{i=1}^{300} \omega_{i} g_{i}\left(V_{i}+\lambda_{i} Q_{i}\right)-\sum_{i=1}^{300}\left(\lambda_{i} Q_{i}^{2}+c_{i} Q_{i}\right)
$$

Maximizing Equation A.6 with respect to $Q_{i}$ yields the profit-maximizing quantity for all underlying components, as follows:

$$
Q_{i}=\frac{500 \theta m \omega_{i} g_{i}}{D}-\frac{c_{i}}{2 \lambda_{i}} .
$$

Substituting Equation A.7 into Equation A.1, we obtain the percentage price change due to manipulation as

$$
\frac{P_{i}-V_{i}}{V_{i}}=\frac{500 \lambda_{i} \theta m \omega_{i} g_{i}}{D V_{i}}-\frac{c_{i}}{2 V_{i}}
$$

It is useful to define a price elasticity $\varepsilon_{i}$ with respect to the proportion of all outstanding shares $S_{i}$ traded by the manipulator. Let

$$
\varepsilon_{i}=\frac{\lambda_{i} Q_{i} / V_{i}}{Q_{i} / S_{i}}=\frac{\lambda_{i} S_{i}}{V_{i}}, \text { so } \quad \lambda_{i}=\frac{\varepsilon_{i} V_{i}}{S_{i}} .
$$

Substituting Equation A.9 into Equation A.8 yields

$$
\frac{P_{i}-V_{i}}{V_{i}}=\frac{500 \theta m \omega_{i} g_{i} \varepsilon_{i}}{D S_{i}}-\frac{c_{i}}{2 V_{i}}
$$

We choose the absolute capitalization-weighted average percentage price change for the index stocks as the tolerable price change $k$. We let $\psi_{i}=\frac{S_{i} V_{i}}{\sum_{j=1}^{300} S_{j} V_{j}}$ be the capitalization-value weight for the $i$ th component stock. Thus, the price change is expressed as

$$
\sum_{i=1}^{300} \psi_{i} \frac{P_{i}-V_{i}}{V_{i}}=\sum_{i=1}^{300} \psi_{i}\left(\frac{500 \theta m \omega_{i} g_{i} \varepsilon_{i}}{D S_{i}}-\frac{c_{i}}{2 V_{i}}\right) \leq k .
$$

Thus, the prudent position limit for the CSI 300 futures market is

$$
\theta^{*}=\frac{D k}{500 m \sum_{i=1}^{300} \psi_{i} \omega_{i} \varepsilon_{i}\left(g_{i} / S_{i}\right)}+\frac{D \sum_{i=1}^{300} \psi_{i}\left(c_{i} / 2 V_{i}\right)}{500 m \sum_{i=1}^{300} \psi_{i} \omega_{i} \varepsilon_{i}\left(g_{i} / S_{i}\right)} .
$$

Because $c_{i}$ is very small relative to $V_{i}$, the second term in Equation A.12 does not matter much. In addition, the CSI 300 index is a value-weighted index, so that $g_{i}=S_{i}$ and we can assume that all $\varepsilon_{i}$ are a constant value $\varepsilon,{ }^{19}$ so Equation A.12 reduces to Equation 1 as follows:

$$
\theta^{*}=\frac{D k}{500 m \varepsilon \sum_{i=1}^{300} \psi_{i} \omega_{i}}
$$

\footnotetext{
${ }^{19}$ Dutt and Harris (2005) set it to 150 . The component stocks of the CSI 300 are large stocks and have stable liquidity, so we also assume that $\varepsilon_{i}$ is a constant value.
} 
B. Derivation of the ceiling for risk-free cash-and-carry arbitrage. We assume that if there is no arbitrage opportunity, the sum of cash flows for underlying stocks and the CSI 300 futures from time $t$ to $T$ are equal to zero. We define the variance as in Table A.1 and list details of the cash flows in Table A.2.

\begin{tabular}{lll|lll}
\hline Parameter & Setting & Note & Parameter & Setting & Note \\
\hline$t_{d}$ & & The trading day at time $t$ & $T_{d}$ & $\begin{array}{l}\text { The trading day at time } \\
T\end{array}$ \\
\hline$S_{t}$ & $\begin{array}{l}\text { Imported from the } \\
\text { real market }\end{array}$ & The price of the CSI 300 index at time $t$ & $S_{T}$ & $\begin{array}{l}\text { The price of the CSI } \\
300 \text { index at time } T\end{array}$ \\
\hline$F_{t}$ & & $\begin{array}{l}\text { The price of the CSI 300 futures at } \\
\text { time } t\end{array}$ & $F_{T}$ & $\begin{array}{l}\text { The price of the CSI } \\
300 \text { futures at time } T\end{array}$ \\
\hline$C_{f t}$ & $0.005 \%$ & Commission for trading futures & $C_{f T}$ & $0.01 \%$ & $\begin{array}{l}\text { Handling fees for } \\
\text { delivery }\end{array}$ \\
\hline$C_{s t}$ & $0.02 \%$ & Handling fees for buying stocks & $C_{s T}$ & $0.12 \%$ & $\begin{array}{l}\text { Handling fees for } \\
\text { selling stocks }\end{array}$ \\
\hline$C_{s i}$ & $0.21 \%$ & Impact cost of stocks & $C_{f l}$ & $0.015 \%$ & Impact cost of futures \\
\hline$r$ & $6 \%$ & Annual risk-free interest rate & $e$ & $15 \%$ & Margin ratio \\
\hline$d$ & 4.1495 & $\begin{array}{l}\text { The sum of all dividends from time } t \text { to } \\
\text { time } T \text { by compounding interest }\end{array}$ & &
\end{tabular}

TABle A.1. Parameter definitions

\begin{tabular}{|c|c|c|}
\hline Items & Cash Flow at day $t_{d}$ & Cash Flow at day $T_{d}$ \\
\hline \multicolumn{3}{|c|}{ Stocks } \\
\hline Buying stocks & $-S_{t}$ & \\
\hline Cost of buying stocks & $-S_{t} C_{s t}-S_{t} C_{s i}$ & \\
\hline Finance for buying stocks & $S_{t}+S_{t} C_{s t}+S_{t} C_{s i}$ & \\
\hline Selling stocks & & $S_{T}$ \\
\hline Cost of selling stocks & & $-S_{T} C_{S T}-S_{T} C_{S i}$ \\
\hline Dividends & & $d$ \\
\hline Paying back the initial lending money & & $-\left(S_{t}+S_{t} C_{s t}+S_{t} C_{s i}\right) \times(1+r)^{\left(T_{d}-t_{d}\right) / 365}$ \\
\hline \multicolumn{3}{|c|}{ Futures } \\
\hline Margin of selling futures & $-F_{t} e$ & \\
\hline Cost of selling futures & $-F_{t} \times C_{f t}-F_{t} C_{f i}$ & \\
\hline Finance for selling futures & $F_{t} e+F_{t} C_{f t}+F_{t} C_{f i}$ & \\
\hline Profit of closing position & & $F_{t}-F_{T}$ \\
\hline Cost of trading futures & & $-F_{T} C_{f T}-F_{T} C_{f i}$ \\
\hline Recovering margin & & $F_{t} e$ \\
\hline Paying back the initial lending money & & $-\left(F_{t} e+F_{t} C_{f t}+F_{t} C_{f i}\right) \times(1+r)^{\left(T_{d}-t_{d}\right) / 365}$ \\
\hline
\end{tabular}

TABLE A.2. Cash flows for risk-free cash-and-carry arbitrage.

As the sum of the cash flows at time $t$ is zero, cash-and-carry arbitrage will be successful when the sum of the cash flows at time $T$ is greater than zero. Assuming that the position is held because of the maturity time $T$ for the futures, we let $S_{t}=S_{T}=F_{T}$ and determine that the ceiling for the no-arbitrage range is

$$
\begin{array}{r}
S_{T}-S_{T} C_{s T}-S_{T} C_{s i}+d-\left(S_{t}+S_{t} C_{s t}+S_{t} C_{s i}\right)(1+r)^{\left(T_{d}-t_{d}\right) / 365}+F_{t}-F_{T}- \\
F_{T} C_{f T}-F_{T} C_{f i}+F_{t} e-\left(F_{t} e+F_{t} C_{f t}+F_{t} C_{f i}\right)(1+r)^{\left(T_{d}-t_{d}\right) / 365}=(\mathrm{A} .13)
\end{array}
$$


Substituting $S_{t}=S_{T}=F_{T}$ into Equation A.13, we can determine the ceiling $F_{t}^{*}$ as the fundamental value $v_{t}$ as follows:

$$
v_{t}=F_{t}^{*}=\frac{S_{T}\left(C_{s T}+C_{s i}+C_{f T}+C_{f i}\right)+S_{t}\left(1+C_{s t}+C_{s i}\right)(1+r)^{\left(T_{d}-t_{d}\right) / 365}-d}{1+e-\left(e+C_{f t}+C_{f i}\right)(1+r)^{\left(T_{d}-t_{d}\right) / 365}} .
$$

Thus, if the CSI 300 futures market price $F_{t}$ is higher than $v_{t}$, traders can engage in risk-free cash-and-carry arbitrage and obtain a positive profit.

C. Genetic algorithm. We describe implementation of the genetic algorithm (GA) for intelligent traders. We use the GA to optimize the forecasting of intelligent traders. The GA with classifier system is revised from the typical GA of the Santa Fe Institution Artificial Stock Market (SFI-ASM) as described by Arthur, Holland, LeBaron, Palmer and Tayler (1997) and Ehrentreich (2008). The key task in applying the SFI-ASM GA to the ACFM is use of a classifier system to describe the ACFM market conditions. Unlike the SFI-ASM, which uses a specialist for market clearing to simplify the market conditions, the ACFM uses a continuous double auction to match orders, so the market conditions are more complex. We redesigned a classifier system and let it use some rules similar to a technical analysis based on the fundamental value $v_{t-\tau}$, the current bid-ask midpoint $p_{t^{\prime}}^{m}$, and the average historical price $\bar{p}_{t, \tau}$. All the classifier rules are listed in Table A.3. The forecasting rule comprise two parts: the condition part describes the condition used according to classified system rules, and the forecasting part consists of the three parameters $x, y$, and $z$ in Equation 4. There are 60 forecasting rules in total. When intelligent trader $i$ enters the market, the forecasting rule whose condition part matches the current market condition is selected for the candidate list. Then the trader chooses the best forecasting rule with the highest historical performance. If no forecasting rule matches the current market condition, the GA generates a new rule for which the condition part is set to match the current market condition and the forecasting part is set randomly. Then the trader uses $x, y$, and $z$ to forecast the current fundamental value according to Equation 4. In brief, GAs use an evolution process including selection, crossover, and mutation to optimize the forecasting rules of intelligent traders. The GA evolution process occurs every 120 periods. When the evolution process is active, the selection process orders forecasting rules according to their historical performance, and the crossover and mutation processes generate a number of new forecasting rules from the rules with high historical performances with an exogenous probability. ${ }^{20}$ The evolution process changes both the market condition and forecasting parts of the forecasting rule. Then the GA uses the new

\footnotetext{
${ }^{20}$ The crossover rate is set to 0.1 and the mutation rate is set to 0.3 .
} 
forecasting rules to replace some old rules with low historical performance ${ }^{21}$ We refer to Wei, Zhang, He and Zhang (2014) for details of the GA in limit order markets.

\begin{tabular}{ll|ll|ll}
\hline Number & Rule & Number & Rule & Number & Rule \\
\hline 1 & $p_{t^{\prime}}^{m} / \bar{p}_{t, \tau}>0.90$ & 10 & $\bar{p}_{t, \tau} / v_{t-\tau}>0.90$ & 19 & $\bar{p}_{t, \frac{\tau}{2}}>\bar{p}_{t, \tau}$ \\
2 & $p_{t^{\prime}}^{m} / \bar{p}_{t, \tau}>0.93$ & 11 & $\bar{p}_{t, \tau} / v_{t-\tau}>0.93$ & 20 & $\bar{p}_{t, \frac{\tau}{4}}>\bar{p}_{t, \frac{\tau}{2}}$ \\
3 & $p_{t^{\prime}}^{m} / \bar{p}_{t, \tau}>0.95$ & 12 & $\bar{p}_{t, \tau} / v_{t-\tau}>0.95$ & 21 & $\bar{p}_{t, \frac{\tau}{6}}>\bar{p}_{t, \frac{\tau}{4}}$ \\
4 & $p_{t^{\prime}}^{m} / \bar{p}_{t, \tau}>0.97$ & 13 & $\bar{p}_{t, \tau} / v_{t-\tau}>0.97$ & 22 & $\bar{p}_{t, \frac{\tau}{12}}>\bar{p}_{t, \frac{\tau}{6}}$ \\
5 & $p_{t^{\prime}}^{m} / \bar{p}_{t, \tau}>1$ & 14 & $\bar{p}_{t, \tau} / v_{t-\tau}>1$ & 23 & $\bar{p}_{t, \frac{\tau}{2}}>v_{t-\tau}$ \\
6 & $p_{t^{\prime}}^{m} / \bar{p}_{t, \tau}>1.03$ & 15 & $\bar{p}_{t, \tau} / v_{t-\tau}>1.03$ & 24 & $\bar{p}_{t, \frac{\tau}{4}}>v_{t-\tau}$ \\
7 & $p_{t^{\prime}}^{m} / \bar{p}_{t, \tau}>1.05$ & 16 & $\bar{p}_{t, \tau} / v_{t-\tau}>1.05$ & 25 & $\bar{p}_{t, \frac{\tau}{6}}>v_{t-\tau}$ \\
8 & $p_{t^{\prime}}^{m} / \bar{p}_{t, \tau}>1.07$ & 17 & $\bar{p}_{t, \tau} / v_{t-\tau}>1.07$ & 26 & $\bar{p}_{t, \frac{\tau}{12}}>v_{t-\tau}$ \\
9 & $p_{t^{\prime}}^{m} / \bar{p}_{t, \tau}>1.10$ & 18 & $\bar{p}_{t, \tau} / v_{t-\tau}>1.10$ & & \\
\hline
\end{tabular}

TABLE A.3. Classification rules.

\section{Fitting maps for the order-size probability density functions for four} investor types. Using account data for order submission, we generated order-size probability-density functions with Matlab for four trader types according to Equation 5. The fitting maps are presented in Figure A.1 and the goodness-of-fit coefficients are listed in Table A.4.

\begin{tabular}{lllll}
\hline Investor type & $\mathrm{SSE}$ & $\mathrm{R}$-square & Adjusted R-square & RMSE \\
\hline Informed traders & 0.002758 & 0.9666 & 0.9655 & 0.00536 \\
Intelligent traders & 0.001149 & 0.9951 & 0.995 & 0.00346 \\
Simple traders & 0.0005317 & 0.9989 & 0.9988 & 0.002353 \\
Liquidity traders & $3.58 \mathrm{E}-05$ & 0.9999 & 0.9999 & 0.0006105 \\
\hline
\end{tabular}

TABLE A.4. Goodness-of-fit coefficients for the order-size probability density functions for four trader types.

\footnotetext{
${ }^{21}$ The replacement rate is set to $10 \%$.
} 


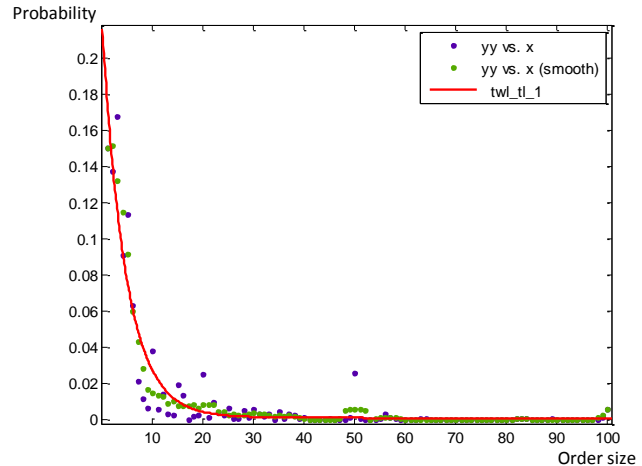

(a) Informed traders

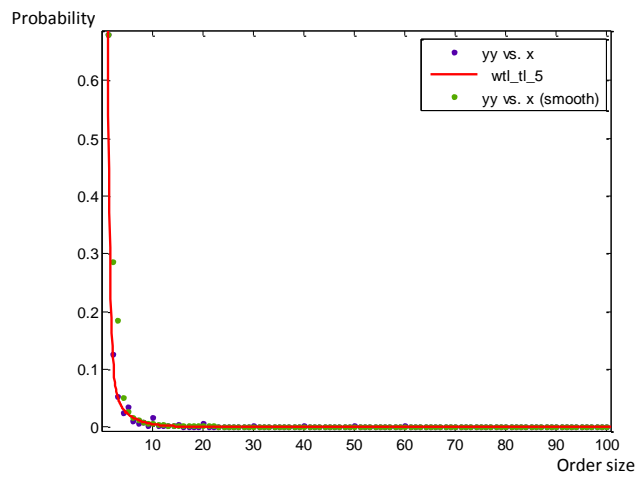

(c) Simple traders

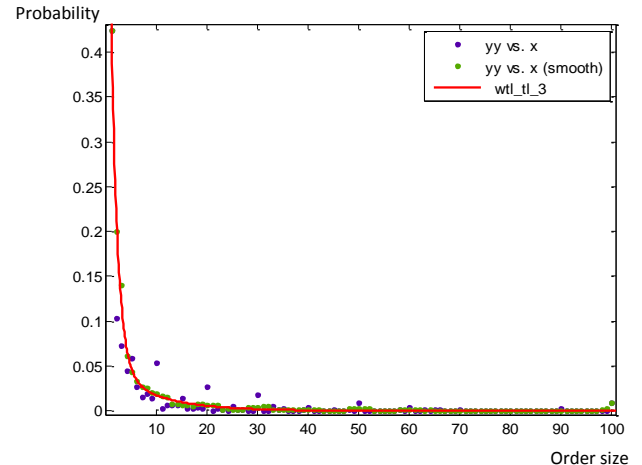

(b) Intelligent traders

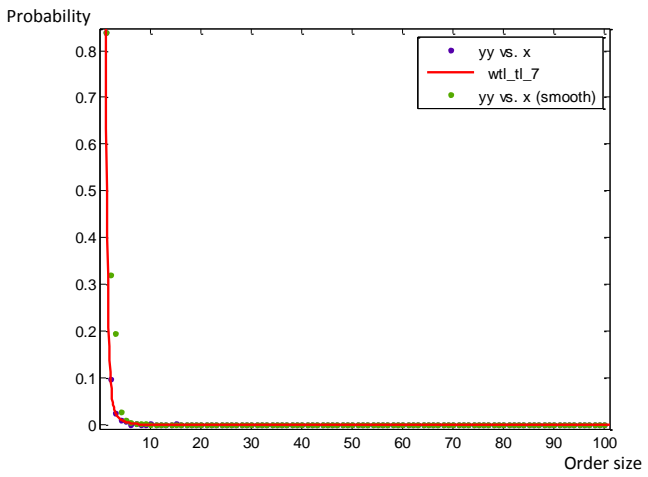

(d) Liquidity traders

FiguRE A.1. Fitting maps for order-size probability density functions for four trader types.

E. Observed market price, order book, and trading volume. Here we provide some observational results from a typical simulation of Experiment 1. Figure A.2 shows the price dynamics for the whole study period. The market price $p_{t}$ has a consistent trend and similar fluctuations to the CSI 300 futures price $p_{I F^{1009}}$. Figure A.3 shows the limit order book for one period; the shape is similar to that for real data. Figure A.4 shows that the trading volume fluctuates in a similar way to the real market volume dynamics. These figures confirm that the ACFM can generate realistic features of the CSI 300 futures market. 


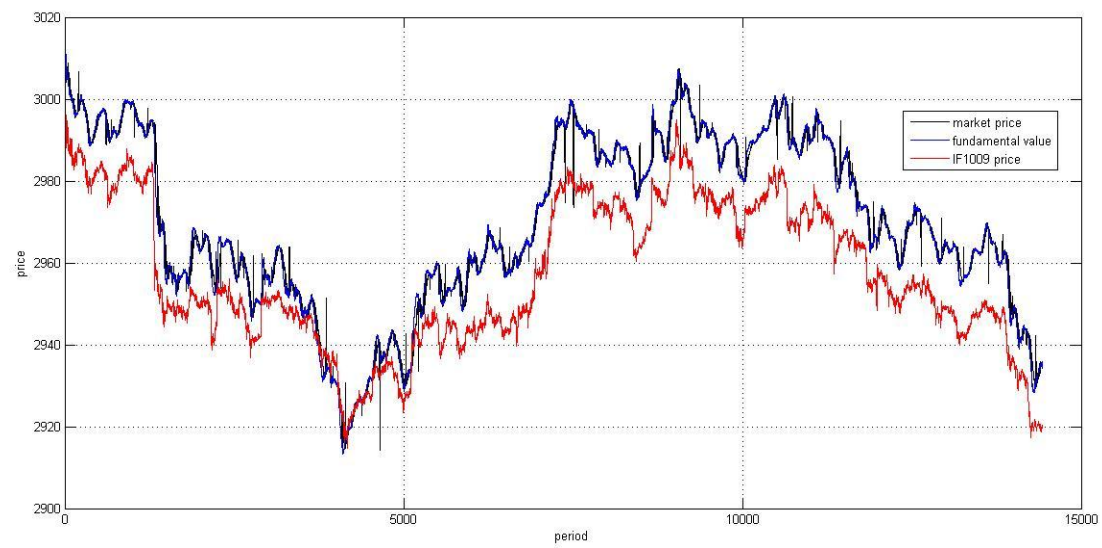

Figure A.2. Price chart for the market price, fundamental value, and real CSI 300 stock futures price over the whole study period.

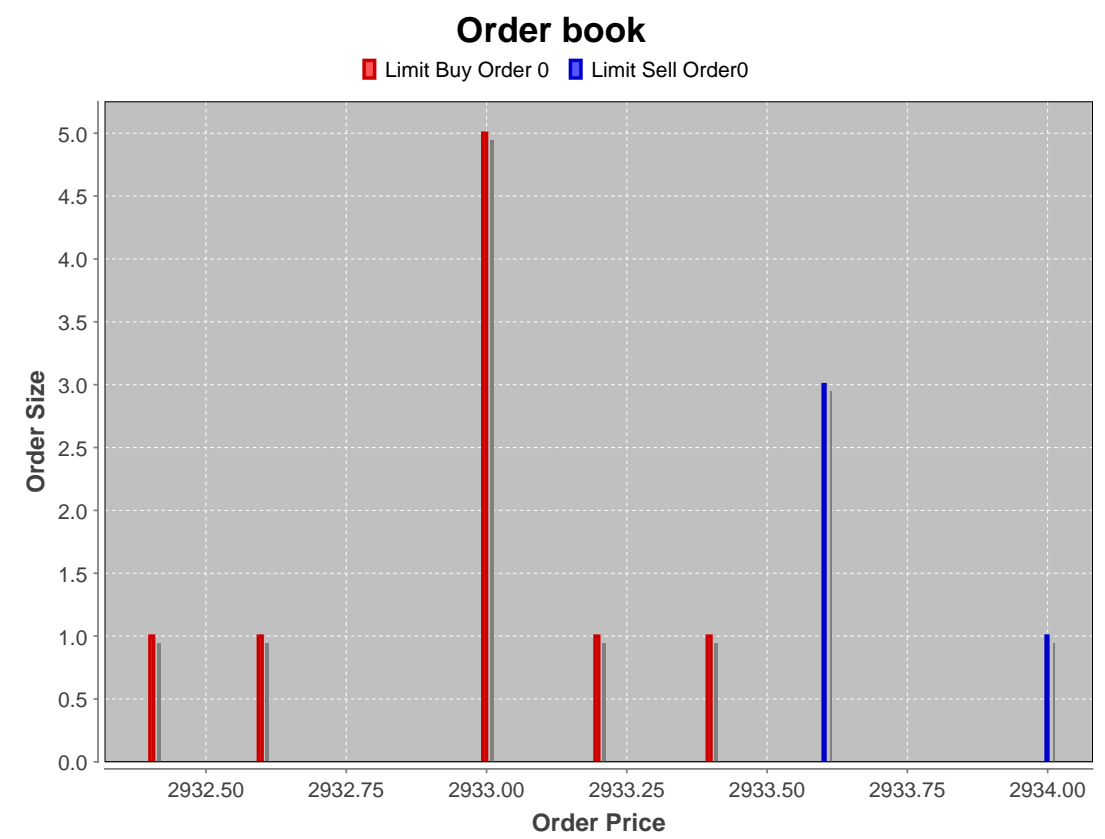

Figure A.3. Order book dynamics for Experiment 1.

\section{REFERENCES}

Almgren, R., Thum, C., Hauptmann, E. and Li, H. (2005), 'Equity market impact', Risk 7, 57-62. Arthur, W., Holland, H., LeBaron, B., Palmer, R. and Tayler, P. (1997), 'Asset pricing under endogenous expectations in an artificial stock market', in The Economy As An Evolving Complex System II, Eds. W. Arthur and S. Durlauf and D. Lane, Addison-Wesley, pp. 15-44.

Chiarella, C., Iori, G. and Perellò, J. (2009), 'The impact of heterogeneous trading rules on the limit order book and order flows', Journal of Economic Dynamics and Control 33(3), 525-537. 


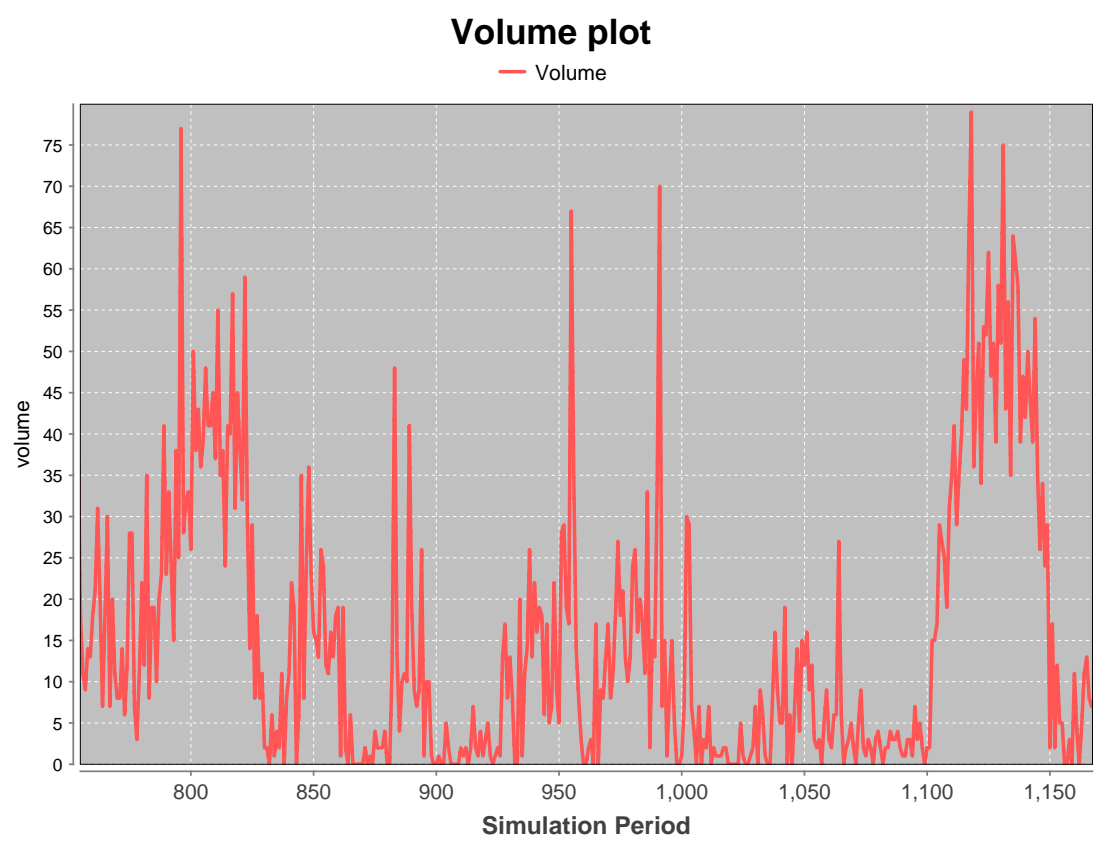

Figure A.4. Volume plot for Experiment 1.

Dawid, H. and Fagiolo, G. (2008), 'Agent-based models for economic policy design: Introduction to the special issue', Journal of Economic Behavior and Organization 67, 351-354.

Dutt, H. and Harris, L. E. (2005), 'Position limits for cash-settled derivative contracts', Journal of Futures Markets 25, 946-965.

Ehrentreich, N. (2008), Agent-based Modeling: The Santa Fe Institute Artificial Stock Market, Springer-Berlin.

Gastineau, G. L. (1991), 'Option position and exercise limits: Time for a radical change', Journal of Portfolio Management 19, 92-96.

Gil-Bazo, J., Moreno, D. and Tapia, M. (2007), 'Price dynamics, informational efficiency and wealth distribution in continuous double auction markets', Computational Intelligence 23, 176-196.

Goettler, R. L., Parlour, C. A. and Rajan, U. (2009), 'Informed traders and limit order markets', Journal of Financial Economics 93(1), 67-87.

Grossman, S. J. (1993), 'The case for eliminating position limits on financial futures', Journal of Financial Engineering 2, 39-42.

Kong, D. and Wang, M. (2014), 'The manipulator's poker: order-based manipulation in the Chinese stock market', Emerging Markets Finance \& 3 Trade 50(2), 73-98.

Kumar, P. and Seppi, D. J. (1992), 'Futures manipulation with "cash settlement", Journal of Finance 47, 1485-1502.

Kyle, A. (1984), 'A theory of futures market manipulations', in Industrial organization of futures markets, Lexington, Mass., pp. 141-173.

Kyle, A. (1985), 'Continuous auctions and insider trading', Econometrica 53(6), 1315-1335.

Menkhoff, L., Osler, C. L. and Schmeling, M. (2010), 'Limit-order submission strategies under asymmetric information', Journal of Banking $\&$ Finance 34, 2665-2677.

Telser, L. G. (1993), 'A review of the case for position limits on agricultural futures', Journal of Financial Engineering 2, 33-38. 
Theissen, E. (2000), 'Market structure, informational efficiency and liquidity: An experimental comparison of auction and dealer markets', Journal of Financial Markets 3(4), 333-363.

Wei, L., Zhang, W., He, X. and Zhang, Y. (2014), The value of learning and liquidity in limit order markets, Working paper (No. 333), Quantitative Finance Research Central (QFRC), University of Technolgy, Sydney.

Wei, L., Zhang, W., Xiong, X. and Zhao, Y. (2014), 'A multi-agent system for policy design of tick size in stock index futures markets', Systems Research and Behavioral Science 31, 512-526.

Xiong, X., Wen, M., Zhang, W. and Zhang, Y. (2011), 'Cross-market financial risk analysis: An agent-based computational finance', International Journal of Information Technology $\&$ Decision Making 10, 563-584. 